\title{
Educação Permanente em Saúde e atenção psicossocial: a experiência do Projeto Rede Sampa
}

\author{
Permanent Health Education and psychosocial care: the experience of \\ the Projeto Rede Sampa
}

Christiane Mery Costa', Claudia Regina de Moraes Abreu1, Paulo Amarante $\mathbf{1}$, Felipe Rangel de

Souza Machado 1

DOI: $10.1590 / 0103-1104202012726$

RESUMO Este artigo relata uma experiência de formação em saúde mental desenvolvida no município de São Paulo entre os anos de 2013 e 2016. Denominado Projeto Rede Sampa - Saúde Mental Paulistana, direcionou-se a trabalhadores de diversas categorias profissionais e diferentes pontos da Rede de Atenção Psicossocial, tendo sido elaborado e executado utilizando estratégias que garantiram a participação dos distintos atores na construção de conteúdos de aprendizagem, a abordagem da singularidade das redes territoriais e o registro do percurso formativo das turmas. A partir da metodologia construcionista social, procurou-se discutir a relevância das interações dialógicas para o fortalecimento do trabalho em rede e a importância do alinhamento com a atenção psicossocial como modelo ético de cuidado.

PALAVRAS-CHAVE Educação continuada. Sistemas de apoio psicossocial. Atenção à saúde. Saúde mental.

\begin{abstract}
This article reports on a training experience in mental health developed in the city of São Paulo between 2013 and 2016. Named Projeto Rede Sampa - Saúde Mental Paulistana, it was aimed at workers from different professional categories and different points of the Psychosocial Care Network, having been elaborated and executed using strategies that ensured the participation of the different actors in the construction of learning contents, the approach to the singularity of territorial networks and the registration of the training path of the classes. Based on the social constructionist methodology, we sought to discuss the relevance of dialogical interactions for the strengthening of networking and the importance of alignment with psychosocial care as an ethical model of care.
\end{abstract}

KEYWORDS Education, continuing. Psychosocial support systems. Health care (public health). Mental health. 


\section{Introdução}

Entre avanços e retrocessos no campo das políticas públicas no Brasil desde a instituição do Sistema Único de Saúde (SUS), movimentos de trabalhadores, usuários e familiares em torno da reforma psiquiátrica e da luta antimanicomial vêm reafirmando a adoção do modelo de atenção psicossocial, orientado por uma ética emancipatória, centrada no acolhimento à experiência singular da existência dos sujeitos e pautada no investimento em práticas sociais capazes de modificar as concepções acerca da doença e diminuir o preconceito social, transformando territórios de vida em lugares de cuidado.

O estabelecimento da Rede de Atenção Psicossocial (Raps) pela Portaria ${ }^{0} 3.088 / 2011^{1}$ institui a diversificação de estratégias de cuidado para pessoas com sofrimento ou transtorno mental, objetivando alcançar a integralidade pela ampliação e articulação de diferentes pontos de atenção. A proposição de estabelecer fluxos assistenciais que envolvam a atenção básica, psicossocial, hospitalar, urgência e emergência, estratégias de residencialidade, desospitalização e inclusão pelas vias do trabalho e cultura requer que os profissionais incluam o paradigma psicossocial no rol de referências reconhecidas e validadas por eles em todos os pontos da rede.

A formação dos trabalhadores em processos de Educação Permanente em Saúde (EPS), conforme preconizado pela Política Nacional de Educação Permanente em Saúde (PNEPS), deve tomar experiências e vivências como geradoras de aprendizagem significativa. No modelo das Redes de Atenção à Saúde (RAS), ela pode ser recurso que suscite movimentos dialógicos e estratégias de negociação entre os agentes de saúde com vistas ao estabelecimento de relações solidárias, ao reconhecimento e constituição de parcerias formais e informais nos territórios, à composição das alternâncias no continuum do cuidado, à validação dos novos saberes e aprendizagens.

Neste artigo, debruçamo-nos sobre a experiência do Projeto Rede Sampa - Saúde Mental
Paulistana (PRS) que conjugou os campos da saúde mental com o da formação dos trabalhadores da saúde como uma possibilidade de engajar os trabalhadores da Raps na atenção psicossocial e de fazer frente aos retrocessos que se prenunciam pelo incentivo às políticas de atendimento que resgatam o modelo asilar.

Com base nas premissas da atenção psicossocial e da EPS, no ano de 2013, a prefeitura de São Paulo firmou parceria com a Secretaria de Gestão do Trabalho e da Educação na Saúde (SGTES) do Ministério da Saúde (MS), buscando promover a qualificação dos profissionais da saúde do SUS atuantes na Raps. O PRS evidenciou a possibilidade de construção coletiva do saber, aproximando trabalhadores e facilitando a criação de novas redes de sociabilidade necessárias ao funcionamento da Raps.

Este relato de experiência é fruto de uma pesquisa $^{2}$ que procurou compreender os sentidos da educação permanente para os profissionais de saúde que participaram do projeto. O recorte foi realizado considerando as ações desenvolvidas entre os anos de 2014 e 2016, abrangendo os cursos de curta duração, com carga horária de 60 horas, na modalidade semipresencial, sendo 32 horas de atividades presenciais e 28 horas de atividades no Ambiente Virtual de Aprendizagem (AVA). O uso do AVA incluiu a elaboração de narrativas coletivas como trabalho de conclusão de curso, que teve por objetivo apresentar a interface entre o conteúdo discutido e o território de trabalho do ponto de vista dos alunos/trabalhadores.

Trata-se de pesquisa qualitativa, com abordagem hermenêutica e utilização da metodologia construcionista social, que analisou a interação e o compartilhamento de saberes ocorridos nos percursos formativos, discutindo a importância das interações dialógicas para aprimorar a organização da rede de cuidados e a produção de sentido na validação das práticas de trabalho. Foram realizados grupos focais e entrevistas com alunos, docentes e coordenadores que dele participaram. A pesquisa foi autorizada pelos Comitês de Ética em Pesquisa da instituição formadora (CAAE: 
91285818.9.0000.5241 - Parecer: 2.804.408) e da Secretaria Municipal de Saúde de São Paulo (CAAE: 91285818.9.3001.0086 - Parecer: 2.858.118).

\section{Delineando um projeto de formação para o trabalho em rede}

Em dezembro de 2012, na transição dos governos municipais, a Secretaria Municipal da Saúde de São Paulo celebrou convênio com a SGTES para a realização de oficinas de atualização dos trabalhadores no campo da saúde mental com transferência de recursos financeiros para a execução da municipalidade.

Como, à ocasião, o município não havia estruturado um projeto de EPS para a Raps, optou-se estrategicamente, no sentido de garantir o recebimento dos recursos, por aderir a um projeto do MS em fase de implantação que envolvia basicamente a realização de três oficinas para capacitação dos trabalhadores para o cuidado em saúde mental:

- Saúde Mental da Infância e Adolescência;

- Atenção às Situações de Crise em Saúde Mental;

- Atualização em saúde mental e trabalho em rede: demandas relacionadas ao consumo de álcool e outras drogas.

Grande parte das capacitações produzidas pelo MS à ocasião tinham seu planejamento realizado de maneira centralizada, sendo elaboradas por conteudistas a partir de questões pertinentes a todo o território nacional. Os docentes, selecionados regionalmente, recebiam capacitação pedagógica e acesso ao material didático a ser utilizado, formato contraditório aos pressupostos pedagógicos da PNEPS que preveem o uso de metodologia problematizadora como geradora da aprendizagem significativa, mediando um caminho que deve colocar em análise a prática dos trabalhadores, estimulando a reflexão crítica e a construção de novos conhecimentos.

O grupo condutor do convênio no município compreendia as ações de EPS como recursos estratégicos para a gestão e organização da atenção à saúde, devendo seguir uma lógica ascendente, descentralizada e transdisciplinar, conforme definido por Ceccim e Feuerwerker ${ }^{3}$. Assim, no ano de 2013, um novo plano de capacitações foi elaborado, com ampliação do escopo do projeto, para cursos de curta duração, aprimoramentos e especializações em saúde mental voltados a profissionais de níveis de escolaridade e formações diversificadas. Avaliações de processo formativo e produção de cadernos temáticos pelos trabalhadores da saúde também foram previstas na proposta denominada Projeto Rede Sampa - Saúde Mental Paulistana (PRS).

Os objetivos do PRS eram a qualificação dos trabalhadores das redes de atenção para o cuidado em saúde mental com foco na manutenção dos vínculos sociais e familiares e na minimização do sofrimento psíquico; a integração e a articulação intersetorial dos diversos serviços no fortalecimento da Raps no município; e a promoção do cuidado em rede na busca da integralidade na atenção à saúde da população a partir da reorganização dos processos de trabalho.

O ponto de partida para a redefinição das ações foi a realização do levantamento das necessidades de capacitação em saúde mental percebidas pelos trabalhadores dos distintos pontos da Raps por meio de instrumental, identificando temas considerados relevantes.

A tarefa de transformar essas necessidades em conteúdo didático-pedagógico passa pela construção dos referenciais teórico-conceituais, elaboração de conteúdos e definição de metodologias de aprendizagem. O foco do PRS no fortalecimento da Raps objetivou transformar a organização territorial em elemento a ser incluído nos debates entre os trabalhadores 
em sala de aula, tendo no docente um mediador das discussões. Era importante que o conteúdo, embora presente e norteador, fosse permeável a novas questões emergentes do encontro entre docentes e alunos, permitindo a ressignificação constante das problemáticas e das potencialidades territoriais.

Os temas apontados pelos trabalhadores foram agrupados em quatro áreas temáticas, e o planejamento dos cursos de curta duração se deu com a constituição de Grupos de Formadores, compostos por coordenadores e docentes de uma mesma área, responsáveis pela elaboração (e reelaboração) das aulas no decorrer do curso (quadro 1). Essa estratégia exigiu encontros rotineiros do grupo e impulsionou um importante apoio mútuo para o fortalecimento da docência.

Quadro 1. Principais características do trabalho do grupo de formadores

\begin{tabular}{|c|c|c|}
\hline Características & Coordenador de Área & Docente \\
\hline Modo de Seleção & Notória especialidade. & Edital de seleção pública. \\
\hline Experiência necessária & $\begin{array}{l}\text { Acadêmica e em coordenação de } \\
\text { cursos. }\end{array}$ & $\begin{array}{l}\text { Docência e atuação na Rede de Aten- } \\
\text { ção Psicossocial. }\end{array}$ \\
\hline \multirow[t]{5}{*}{ Atribuições } & $\begin{array}{l}\text { Elaborar ementas de curso a partir } \\
\text { da necessidade identificada pelos } \\
\text { trabalhadores. Indicar os referenciais } \\
\text { teóricos e bibliografia. }\end{array}$ & Ministrar aulas. \\
\hline & $\begin{array}{l}\text { Participar de Rodas de Conversa } \\
\text { Regionais, discutindo questões dos } \\
\text { diferentes territórios de trabalho. }\end{array}$ & - \\
\hline & $\begin{array}{l}\text { Coordenar reuniões de capacitação } \\
\text { inicial com docentes, elaborando os } \\
\text { planos de aula. }\end{array}$ & $\begin{array}{l}\text { Participar das reuniões com os Coor- } \\
\text { denadores de Área. }\end{array}$ \\
\hline & $\begin{array}{l}\text { Desenvolver material para a Plata- } \\
\text { forma Moodle }{ }^{\circledR} \text { e as questões dis- } \\
\text { paradora da produção do texto das } \\
\text { Narrativas Coletivas. }\end{array}$ & $\begin{array}{l}\text { Acompanhar e estimular o desenvol- } \\
\text { vimento das atividades no Ambiente } \\
\text { Virtual de Aprendizagem. }\end{array}$ \\
\hline & $\begin{array}{l}\text { Realizar acompanhamento mensal } \\
\text { com os docentes fazendo ajustes no } \\
\text { conteúdo a partir de indicações dos } \\
\text { docentes. }\end{array}$ & $\begin{array}{l}\text { Apresentar no grupo de formadores } \\
\text { as reflexões acerca dos conteúdos } \\
\text { trabalhados e sua correlação com } \\
\text { a rede territorial local, colaborando } \\
\text { nos ajustes da ementa e dos planos } \\
\text { de aula. }\end{array}$ \\
\hline
\end{tabular}

Segundo Ceccim e Feuerwerker,

[...] os saberes formais devem estar implicados com movimentos de autoanálise e autogestão dos coletivos da realidade, pois são os atores do cotidiano que devem ser protagonistas da mudança de realidade desejada pelas práticas educativas $^{3(62)}$.
As diversas estratégias adotadas devem, sob essa perspectiva, partir de uma compreensão de teoria e prática como elementos indissociáveis.

Antecedendo o início de cada um dos cursos, foram realizadas 'rodas de conversas regionais' - encontros entre o coordenador de área e os trabalhadores de macrorregiões municipais - com objetivo de apresentar as 
principais abordagens propostas para os cursos e acolher dos trabalhadores as particularidades territoriais, principais determinações sociais de saúde, modos de organização dos serviços e da rede. Os tópicos emergentes dessas rodas foram posteriormente incorporados às ementas dos cursos.

Dando início aos cursos propriamente ditos, as turmas de alunos/trabalhadores foram constituídas de modo heterogêneo tanto em relação à escolaridade quanto à formação e inserção nas unidades de trabalho. Dependendo da avaliação regional no que se refere à pertinência de ativação das redes intersetoriais, também foi possibilitada a participação de profissionais externos à saúde, tais como defensores públicos, conselheiros tutelares, profissionais da assistência social e educação, em um exercício de ampliação na problematização da rede de cuidados.

É um curso na área de saúde mental, mas que não era só pra Caps. Permite ferramentas e instrumentos ao trabalhador de qualquer equipamento - da UBS, ou do CER, ou do Caps - ele se apropria disso e pode repensar sua intervenção. Pelo menos pra você refletir o que você faz, e internalizar ao seu estilo aquilo que você tá aprendendo. (Trabalhador 2).

O território de trabalho foi o ponto de convergência do olhar de docentes e alunos/ trabalhadores, singularizando o processo formativo de cada turma, sendo facilitador para a caracterização coletiva das vulnerabilidades e principais determinações sociais do sofrimento psíquico, para o reconhecimento dos recursos formais e informais disponíveis na organização do cuidado e apresentação de estratégias e intervenções inovadoras capazes de potencializar o trabalho em rede.

Os cursos foram ofertados em módulos independentes, ou seja, sem se constituírem pré-requisitos sequenciais entre si. Organizálos em áreas temáticas pretendeu tecer um fio condutor entre eles, produzindo um sentido de continuidade a partir de referenciais teórico-conceituais comuns ao campo psicossocial.

\section{Construindo bases teórico- conceituais para validação da atenção psicossocial}

A perspectiva construcionista social, base metodológica da pesquisa que procurou investigar os sentidos da educação permanente no PRS, compreende o conhecimento como resultado de uma construção social, e não como reflexo da apreensão do mundo tal qual ele se apresenta. Segundo Souza ${ }^{4}$, o status de real de um dado fenômeno é conferido por critérios de legitimidade assumidos como verdade por uma comunidade.

Enquanto empreendimento interativo, as práticas sociais em uso pelos indivíduos passam de maneira constante por movimentos de significação e de ressignificação que ora as ratificam, ora as retificam. É a 'produção de sentido' que valida o conhecimento construído no coletivo a partir de movimentos de desfamiliarização com rituais tomados como óbvios nos grupos sociais. Por meio de jogos de posicionamentos nos grupos, constituem-se os acordos que validam verdades e legitimam o conhecimento 5 .

Validar a atenção psicossocial em toda a Raps implica, portanto, a discussão e o questionamento das práticas asilares em uso pelos profissionais em todos os pontos de atenção e reelaboração de novo tecido de significados para o cuidado. Como afirma Rotelli6(43):

Devemos partir do pressuposto de que no mundo ainda existem milhões de pessoas dentro dos hospitais psiquiátricos, que existem novas formas de internação através de condicionamentos farmacológicos pesados. Existe um internamento farmacológico quando, através dos remédios, nós reduzimos o corpo de uma pessoa a corpo inerte. Existe um internamento psicológico quando reduzimos a pessoa a sua doença. Contra todas estas formas de internamento temos uma luta infinita ainda a ser feita e a estratégia para combate nesta luta se dá através dos profissionais que devem aprender 
os novos saberes, que devem aprofundar-se neste tema da complexidade das relações do corpo social.

Costa-Rosa ${ }^{\mathbf{7 ( 1 4 4 )}}$ analisa as concepções das práticas em saúde mental em duas esferas indissociáveis e distintas entre si: a esfera político-ideológica e a teórico-técnico. Para ele, só

é possível considerar que dois modelos de atuação no campo da saúde mental são alternativos se são contraditórios. E dois modelos serão contraditórios se a essência das suas práticas se encaminhar em sentidos opostos quanto a seus parâmetros basilares.

$\mathrm{O}$ autor ressalta ainda que o resgate da dignidade e da cidadania abordado no modelo psicossocial, que tem sido amplamente referenciado pelos movimentos antimanicomiais, insere-se na dimensão político-ideológica. No entanto, é de fundamental importância elucidar o paradigma psicossocial também nos seus aspectos teórico-técnicos, pensando nos modos de respostas construídos para fazer frente às abordagens do que ele nomeou modelo asilar.

Amarante ${ }^{\mathbf{8 ( 6 3 )}}$ salienta que a saúde mental deve ser considerada como um processo social

complexo [que] se constitui enquanto entrelaçamento de dimensões simultâneas, que ora se alimentam, ora são conflitantes; que produzem pulsações, paradoxos, contradições, consensos, tensões.

Essa concepção remete a movimento, transformação, percurso em que se reafirmam paradigmas ou se estruturam rupturas que fazem caminhar a compreensão da loucura enquanto fenômeno e delinear as bases da atenção psicossocial em contraposição ao modelo manicomial. O autor define quatro dimensões inerentes a esse processo: teórico-conceitual, jurídico-política, técnico-assistencial e sociocultural.
A 'dimensão teórico-conceitual' constitui as bases epistemológicas do desenvolvimento do campo enquanto ciência. Basaglia, citado por Amarante $^{\mathbf{8}}$, destaca que a psiquiatria separa o objeto fictício, a doença, da existência global e complexa dos sujeitos e do corpo social, sendo ela, a doença, e não o sujeito que a vivencia, o objeto de seu desenvolvimento científico. $\mathrm{O}$ campo psicossocial se direciona a colocar 'a doença entre parênteses' como uma nova possibilidade de produzir conhecimento a partir da implicação com a experiência do sujeito, o que não significa negar a doença como produtora de sofrimento, e, sim, direcionar o foco epistêmico aos sujeitos e sua trajetória de vida, construída por determinações sociais, históricas, culturais que reafirmem múltiplas possibilidades de ser e de viver ${ }^{8}$.

A 'dimensão técnico-assistencial' refere-se aos espaços de produção de cuidado, que devem se voltar a analisar os problemas do cotidiano e intervir neles: relações pessoais, sociais, trabalho, lazer, moradia. Os serviços assistenciais são compreendidos como “dispositivos estratégicos, com o lugares de acolhimento, de cuidado e de trocas sociais [...] lugares de sociabilidade e produção de subjetividade"8(69).

A ‘dimensão jurídico-política’ se constitui enquanto campo de disputa estratégica na construção de cidadania, sendo impulsionada pelos movimentos sociais no tensionamento de agendas governamentais e na consolidação de marcos legais e mecanismos garantidores dos direitos humanos.

Por fim, a 'dimensão sociocultural' tem como horizonte a constituição de um novo projeto de sociedade, uma real possibilidade de transformação social, visto que se fundamenta no envolvimento de toda a sociedade na discussão sobre o paradigma da loucura. A criação de projetos culturais e espaços coletivos de convivência traz grande contribuição para a alteração do lugar social dos sujeitos em sofrimento psíquico. Segundo Basaglia, a relação da sociedade com esses sujeitos não deve ser fundamentada em sentimentos de 
tolerância, mas na evocação de sentidos de reciprocidade e solidariedade.

Com o intuito de abranger todas essas dimensões, os cursos de curta duração do PRS se configuraram em torno de quatro áreas temáticas, desenvolvendo, no período de análise, nove cursos de curta duração. A tabela 1 apresenta as áreas, os cursos e o quantitativo de turmas e de trabalhadores participantes.

\begin{tabular}{|c|c|c|c|}
\hline Área Temática & Cursos & $\begin{array}{r}\text { № de } \\
\text { turmas }\end{array}$ & $\begin{array}{r}\text { № de } \\
\text { participantes }\end{array}$ \\
\hline \multirow{2}{*}{$\begin{array}{l}\text { Atenção à saúde mental da } \\
\text { infância e adolescência }\end{array}$} & Atendimento familiar. & 28 & 822 \\
\hline & $\begin{array}{l}\text { Vulnerabilidades e situações de risco psicossocial na infân- } \\
\text { cia e adolescência: abordagem e linhas de cuidado integral. }\end{array}$ & 18 & 252 \\
\hline \multirow{2}{*}{$\begin{array}{l}\text { Atenção à saúde mental } \\
\text { do adulto e às situações } \\
\text { de crise }\end{array}$} & $\begin{array}{l}\text { Manejo e conceituação ampliada da crise em saúde men- } \\
\text { tal. }\end{array}$ & 20 & 496 \\
\hline & Psicopatologia, Psicofarmacologia e Medicalização. & 18 & 514 \\
\hline \multirow[t]{2}{*}{$\begin{array}{l}\text { Atenção à saúde dos } \\
\text { usuários de Substâncias } \\
\text { Psicoativas }\end{array}$} & $\begin{array}{l}\text { Histórico e Epidemiologia do uso de drogas: da visão redu- } \\
\text { cionista da doença à Política de Atenção à Saúde Mental, } \\
\text { álcool e outras drogas. }\end{array}$ & 24 & 652 \\
\hline & $\begin{array}{l}\text { A Redução de danos: conceituação, mitos e estratégias de } \\
\text { ação no território e com população vulnerável. }\end{array}$ & 19 & 339 \\
\hline \multirow[t]{3}{*}{$\begin{array}{l}\text { Rede de atenção Psicos- } \\
\text { social }\end{array}$} & $\begin{array}{l}\text { O SUS, a Reforma Psiquiátrica e os desafios para o fortale- } \\
\text { cimento da Rede de Atenção Psicossocial. }\end{array}$ & 20 & 547 \\
\hline & Matriciamento.* & 25 & 2.896 \\
\hline & Linhas de cuidado integral e Projeto Terapêutico Singular.* & 22 & 2.435 \\
\hline Total & & 194 & 8.953 \\
\hline
\end{tabular}

\section{O paradigma psicossocial permeando o trabalho na Raps: a construção de sentidos no PRS}

Os entrevistados da pesquisa referiram que o projeto abrangeu múltiplas dimensões do processo referido por Amarante, partindo da compreensão das determinações sociais, históricas, culturais do sofrimento psíquico e considerando que a produção de cuidado deve permear uma rede de sustentação constituída na intersetorialidade.

A área de 'Atenção à saúde mental da infância e da adolescência' discutiu as temáticas do atendimento familiar e principais vulnerabilidades territoriais nos primeiros ciclos de vida, abordando o sofrimento psíquico a partir das determinações sociais e identificando a interface entre os diversos setores sociais nos quais os usuários se inserem.

É uma dimensão não só individual, do sofrimento psíquico: a ideia de um sofrimento que também tem causas, motivos, nos traumas sociais, na retraumatização, nas experiências de desenraizamento, migração, [...] reconhecer que o sofrimento psíquico é de alta complexidade. Não pode ser lido numa interpretação exclusivamente bioquímica ou moral. (Docente 2). 
$\mathrm{Na}$ área de 'Atenção à saúde mental do adulto e as situações de crise', foram abordados os temas de conceito e manejo da crise, assim como da psicopatologia, psicofarmacologia e medicalização. Verifica-se, nas entrevistas, a compreensão da loucura e do sofrimento psíquico como parte da existência do sujeito e, a partir dela, as múltiplas possibilidades de cuidado que se apresentem como alternativa aos processos de patologização e de medicalização da vida. Relatos de trabalhadores entrevistados apontam que essas abordagens tiveram repercussão nas equipes, mesmo mediante a cultura medicamentosa dos serviços.

É possível cuidar de uma paciente sem medicação? Foi uma temática que gerou bastante problematização, em sala de aula, porque o professor trouxe alguns exemplos de experiências internacionais: acompanhar o usuário num quadro psicótico sem intervenção medicamentosa [...]. Isso também serviu um pouco pra gente na realidade de Caps pensar nos usuários que não aceitam intervenção medicamentosa estão em crise e a gente vai pelo vínculo, no cuidado de uma forma mais ampliada. (Trabalhador 2).

Em 'Atenção à saúde dos usuários de Substâncias Psicoativas', foram abordadas as intervenções centradas em aspectos proibicionistas, apresentando a redução de danos como possibilidade de enfoque no cuidado a partir do respeito às escolhas individuais.

Uma coisa que a gente discutiu bastante foi a legalização das drogas. Tinha evidentemente as pessoas que eram a favor e contra ali, mas a gente foi colocando quais seriam as possibilidades se você pudesse ter outro contexto. Então ninguém estava forçando ninguém a mudar de ideia, mas como seria o usuário que poderia chegar ao Caps sem vergonha, ou sem medo porque ele estava usando crack. [...] Outra coisa que a gente discutiu muito foi a droga como um negócio na nossa sociedade, um negócio como outro qualquer, como o capitalista da indústria farmacêutica. (Trabalhador 2).
Os debates promovidos pelos docentes que atuaram na área da 'Rede de Atenção Psicossocial' abordaram a dimensão jurídico-política, discorrendo sobre a importância dos movimentos da reforma sanitária na constituição do SUS, a reforma psiquiátrica e o modelo de trabalho da Raps. Na abordagem do 'Matriciamento' e 'Linha de cuidado', houve mudança na estratégia de trabalho, iniciando um debate sobre a rede no território a partir de suas determinações e potencialidades, conduzindo trabalhadores de diferentes unidades à formação de coletivos. Essa metodologia de trabalho abordou a dimensão sociocultural, apoiando-se em conteúdos estruturados radicalmente sobre a realidade territorial, suas redes formais, informais, ativas e passíveis de serem ativadas, tendo como pano de fundo as teorias que sustentam a atenção psicossocial.

O que estava presente como eixo condutor era a construção da rede. Não havia um conteúdo específico... teve uma variação muito maior que dependeu do território [...] a ideia de construção de rede que estava na base da relação com os outros, a relação entre os equipamentos e as formas de cuidado. (Docente 2).

A disseminação dessas discussões acerca das dimensões da atenção psicossocial aos trabalhadores das unidades de saúde de diferentes complexidades, em especial para as equipes da Atenção Básica, permitiu direcionar o olhar para a compreensão das queixas, sofrimentos e dores tão comuns no cotidiano de trabalho dos profissionais.

Nesse sentido, os processos formativos devem possibilitar não somente a discussão sobre a abordagem individual do cuidado, mas também impulsionar o debate sobre as múltiplas determinações do sofrimento e interrogar a implicação de suas práticas nos modos de produzir saúde pública e coletiva, na reprodução dos processos de patologização e de medicalização da vida e mercantilização da saúde. 


\section{Sistematizando o conhecimento em narrativas coletivas}

O objetivo de fortalecimento da Raps orientou-se pelo estímulo à constituição de uma rede viva e à produção de conexões que ampliassem, para os trabalhadores dos diferentes serviços, oportunidades d e encontros, estabelecimento de compromissos e validação de novas práticas baseadas na atenção psicossocial. Os processos dialógicos foram considerados estratégias geradoras de sentido para o coletivo, visto que possibilitavam a reinterpretação dos fenômenos e a reflexão, convocando sujeitos a um posicionamento e possibilitando a institucionalização e a socialização de novas práticas sociais ${ }^{2}$.

Um dos efeitos positivos do PRS foi colocar em contato direto sujeitos que se relacionariam apenas institucionalmente. Machado, Guizardi e Lemos ${ }^{\mathbf{1 0 ( 6 )}}$ chamam atenção para o fato de que são as dinâmicas relacionais que constituem "redes de sociabilidades nas quais se ancora, de modo sempre instável e singular, os modos de funcionamento institucional". Relatos dos entrevistados ressaltaram esse aspecto, mencionando que a criação de novos vínculos permitiu a melhoria na condução do trabalho em rede.

Ali na sala de aula a gente conseguia ver acontecer o que se espera que aconteça fora da sala de aula: a rede se organizar e se potencializar a partir de uma discussão de caso, ou de um conceito que os provocavam a pensar. Neste sentido, as pessoas se conectavam, pessoas que não se conheciam, serviços que não se conheciam [...] essa diversidade sempre foi muito potente no Rede Sampa, e eu acho que isso precisa ser sustentado em todos os cursos: desde a ACS até o médico, dialogando. (Docente 2).

Os espaços de formação constituídos no PRS objetivaram ampliar essas redes de sociabilidade na perspectiva de questionar as formas de cuidado por meio da construção coletiva do conhecimento, como destaca a entrevistada:

O curso teve essa potência de convocar ao debate, a um posicionamento em relação aos saberes e recuperar o lugar do sujeito que está sendo cuidado.. que o profissional pudesse questionar seus referenciais teóricos, ideológicos pra poder ver quem ele está cuidando de outra forma. (Docente 2).

Reconhecer a interação social como espaço de legitimação do conhecimento implica considerar os processos dialógicos como articuladores dos jogos de posicionamentos nos grupos que dão sentido às experiências humanas e sustentam as práticas sociais 5 . A linguagem é aqui compreendida não como sistema de representação de fatos e fenômenos, mas como atividade humana produtora de realidade em si, produtora de verdade.

Desse modo, a elaboração de um texto, nomeado 'narrativa coletiva', foi o processo de sistematização do saber comum às turmas dos cursos, possibilitando aos profissionais que participaram do PRS registrar a mediação dialógica entre conteúdos e referenciais desenvolvidos nos cursos, território de trabalho e práticas de cuidado ali desenvolvidas. A abertura desse espaço narrativo possibilita a reconstrução das experiências de forma reflexiva, a compreensão do seu fazer, de seu estar no mundo, teorizando a própria experiência"1.

Constituídos na modalidade semipresencial, os cursos de curta duração do PRS tiveram nas aulas presenciais o ambiente de encontro e constituição de dialogicidade. O AVA se estabeleceu como recurso com baixa exigência de tarefas, sendo encarado como repositório virtual de vídeos, slides, filmes, artigos, links, artigos, referências bibliográficas, enfim, todo material didático-pedagógico. Também no AVA, foram elaboradas as 'narrativas coletivas'.

A ferramenta Wiki, disponível na Plataforma Moodle $^{\circledR}$, é voltada à construção de trabalhos colaborativos. A partir de questões abordadas na aula presencial, perguntas disparadoras foram colocadas na plataforma para que os 
participantes escrevessem suas reflexões pessoais, tendo em vista uma aproximação entre o conteúdo da aula e a vivência do trabalho. Construídos no decorrer do curso, esses registros possibilitaram a elaboração final de uma Narrativa alusiva à caracterização das principais vulnerabilidades territoriais, recursos disponíveis, reconhecimento de parceiros formais e informais na efetivação do cuidado, apresentação de intervenções construídas pelos trabalhadores e pelas comunidades, conferindo contorno e materialidade ao conhecimento comum àquele grupo.

Indo além da execução da tarefa proposta de registro do trabalho, pudemos observar que as Narrativas se constituíram como espaço ampliado de ensino-aprendizagem, visto que adentraram o espaço da sala de aula e revelaram-se ferramenta do trabalho do docente, produzindo reflexão sobre a práxis instituída e possibilitando novos modos de pensar o cuidado ${ }^{12}$.

\section{Conclusões}

O PRS foi elaborado a partir de uma diversidade de ações, reunindo grupos heterogêneos de trabalhadores de diferentes níveis de atenção; e, a partir das diretrizes estabelecidas pela PNEPS, desenvolveu ações em abordagens transdisciplinares, embasadas nas necessidades de aprendizagem identificadas pelos trabalhadores no seu fazer cotidiano.

Do ponto de vista pedagógico, a elaboração das aulas realizada de forma aberta e processual produziu movimentos de coautoria entre coordenadores e docentes, facilitou a permeabilidade do currículo às práticas dos profissionais e às singularidades das redes territoriais e estabeleceu espaços de acolhimento, escuta e troca para o grupo de formadores.

O campo da saúde mental, pela característica de questionamento acerca da normatividade social constituinte dos paradigmas psicossocial ou asilar, envolve debates que apresentam, por um lado, possibilidades de acolhimento a modos plurais de viver, direito à liberdade, ampliação da contratualidade social e, por outro, a institucionalização, a segregação ou o isolamento social e a invalidação de produções subjetivas. As discussões acerca dos paradigmas do cuidado em saúde mental nem sempre estão presentes nas trajetórias dos trabalhadores da atenção básica, das unidades hospitalares ou das especialidades, o que aponta para a necessidade de discutir o modelo de atenção que embasa as práticas de trabalho nesses serviços. Questões como o uso de substâncias psicoativas, medicalização e patologização da vida carregam uma grande carga de estigmas e de preconceitos, mesmo entre profissionais da saúde.

Assim, do ponto de vista de fortalecimento da atenção psicossocial pelos diversos pontos de atenção da rede, as ações desenvolvidas possibilitaram aos trabalhadores o reconhecimento dos parceiros do território de trabalho, a apresentação das problemáticas comuns, a elaboração de encaminhamentos conjuntos e de novas estratégias alinhadas ao modelo psicossocial considerando, para além de determinantes biológicos, a abordagem das determinações sociais, econômicas, culturais, afetivas do sofrimento psíquico.

Materializando a importância conferida aos saberes construídos no cotidiano dos territórios, as narrativas coletivas fizeram a interface teoria/prática, configurando-se como uma possibilidade de extensão do espaço das salas aulas, bem como apresentando cuidado, respeito e valorização dos saberes construídos no cotidiano pelos profissionais da rede.

A formação dos trabalhadores em processos de EPS com enfoque nas necessidades das equipes de saúde pode ser diversificada e favorecer a articulação dos diferentes pontos de atenção a partir de metodologias de ensino que considerem a heterogeneidade profissional, a natureza diversa dos serviços e as singularidades territoriais. Esses processos formativos permitem que os grupos possam compreendem fenômenos, conferir sentido às experiências, constituir referenciais comuns e validar o conhecimento produzido no coletivo 
em espaços de mobilização, compartilhamento de saberes e estabelecimento de novas práticas sociais.

\section{Colaboradores}

Autores tiveram tarefas distintas: Costa CM (0000-0001-8105-995X)* contribuiu para a concepção, planejamento, análise e interpretação dos dados. Abreu CRM (0000-00030654-663X)* contribuiu para a aprovação da versão final do manuscrito. Amarante $P$ (0000-0001-6778-2834)* e Machado FRS (0000-0002-5028-8888)* contribuíram para a revisão crítica do conteúdo e para a aprovação da versão final do manuscrito.

\section{Referências}

1. Brasil. Ministério da Saúde. Portaria n ${ }^{0} 3.088$, de 23 de dezembro de 2011. Institui a Rede de Atenção Psicossocial para pessoas com sofrimento ou transtorno mental e com necessidades decorrentes do uso de crack, álcool e outras drogas, no âmbito do Sistema Único de Saúde (SUS). Diário Oficial da União [internet]. 24 Dez 2011 [acesso em 2021 jan 19]. Disponível em: http://bvsms.saude.gov.br/bvs/saudelegis/ gm/2011/prt3088_23_12_2011_rep.html.

2. Costa CM. Os sentidos da educação permanente em saúde para o trabalho em rede: análise de uma experiência na Rede Psicossocial do município de São Paulo [dissertação]. [Rio de Janeiro]: Fundação Oswaldo Cruz; 2019. 100 p.

3. Ceccim RB, Feuerwerker LCM. O quadrilátero da formação para a área da saúde: ensino, gestão, atenção e controle social. Physis. 2004; 14(1):41-65.
4. Souza L. Discurso construcionista social: uma apresentação possível. In: Guanaes C, Moscheta M, Corra-
di-Webster C, et al., organizadores. Construcionismo social: discurso, prática e produção do conhecimento. Rio de Janeiro: Instituto Noos; 2014. p. 49-7.

5. Spink MJ. Práticas discursivas e produção de sentidos no cotidiano. Rio de Janeiro: Centro Edelstein de Pesquisas Sociais; 2013.

6. Rotelli F. Formação e construção de novas instituições em saúde mental. In: Amarante P, Cruz LB, organizadores. Saúde Mental, formação e crítica. Rio de Janeiro: Fiocruz; 2015. p. 37-50.

7. Costa-Rosa A. O modo psicossocial: um paradigma das práticas substitutivas ao modo asilar. In: Amarante P, organizador. Ensaios: subjetividade, saúde mental, sociedade. Rio de Janeiro: Fiocruz; 2000. p. 141-168.

8. Amarante P. Saúde mental e atenção psicossocial. 4. ed. Rio de Janeiro: Fiocruz; 2013. p. 62-81. 
9. Basaglia F. Saúde/doença. In: Amarante P, Cruz LB, organizadores. Saúde Mental, formação e crítica. Rio de Janeiro: Fiocruz; 2015. p. 17-36.

10. Machado FRS, Guizardi FL, Lemos ASP. A burocracia cordial: a implantação da estratégia de apoio institucional na política nacional de atenção básica em saúde. Trab. educ. saúde. 2019; 17(3):1-26.

11. Cunha MI. Conta-me agora! As narrativas como al- ternativas pedagógicas na pesquisa e no ensino. Rev.

Fac. Educ. 1997; 23(1-2):185-195.

12. Abreu CRGM. A narrativa como estratégia de formação na educação em saúde [dissertação]. [Rio de Janeiro]: Fundação Oswaldo Cruz; 2019. 110 p.

Recebido em 13/11/2019

Aprovado em 18/09/2020

Conflito de interesses: inexistente

Suporte financeiro: não houve 